\title{
The involvement of parents in the healthcare provided to hospitalzed children
}

\author{
Elsa Maria de Oliveira Pinheiro de Melo ${ }^{1}$ \\ Pedro Lopes Ferreira ${ }^{2}$ \\ Regina Aparecida Garcia de Lima ${ }^{3}$ \\ Débora Falleiros de Mello ${ }^{4}$
}

Objective: to analyze the answers of parents and health care professionals concerning the involvement of parents in the care provided to hospitalized children. Method: exploratory study based on the conceptual framework of pediatric healthcare with qualitative data analysis. Results: three dimensions of involvement were highlighted: daily care provided to children, opinions concerning the involvement of parents, and continuity of care with aspects related to the presence and participation of parents, benefits to the child and family, information needs, responsibility, right to healthcare, hospital infrastructure, care delivery, communication between the parents and health services, shared learning, and follow-up after discharge. Conclusion: the involvement of parents in the care provided to their children has many meanings for parents, nurses and doctors. Specific strategies need to be developed with and for parents in order to mobilize parental competencies and contribute to increasing their autonomy and decisionmaking concerning the care provided to children.

Descriptors: Child, Hospitalized; Parents; Nursing.

\footnotetext{
${ }^{1} \mathrm{PhD}$, Professor, Escola Superior de Saúde, Universidade de Aveiro, Aveiro, Portugal.

2 PhD, Associate Professor, Faculdade de Economia, Universidade de Coimbra, Coimbra, Portugal.

${ }_{3}$ PhD, Full Professor, Escola de Enfermagem de Ribeirão Preto, Universidade de São Paulo, WHO Collaborating Centre for Nursing Research Development, Ribeirão Preto, SP, Brazil.

${ }^{4} \mathrm{PhD}$, Associate Professor, Escola de Enfermagem de Ribeirão Preto, Universidade de São Paulo, WHO Collaborating Centre for Nursing Research Development, Ribeirão Preto, SP, Brazil.
} 


\section{Introduction}

The participation of parents in the care provided to hospitalized children is a topic under study, showing that hospitals are not a family environment and which causes changes in parental roles ${ }^{(1-4)}$. The hospitalization of children requires improved communication to be established with parents and appropriate information to be provided ${ }^{(4-5)}$, while the performance of care activities needs to be negotiated. Both barriers and facilitators are observed in the participation of parents in the care provided to these children(6).

Knowledge concerning the needs of parents while attending to a sick child in the hospital environment shows that parents become interested and involved in pediatric care, which contributes to qualified and humanized care delivery ${ }^{(7)}$

There are recent publications in this periodical highlighting the importance of analyzing how parents, caregivers and health care professionals recognize adverse events in the care provided to hospitalized children, showing changes in the organization of health facilities, moving toward a culture of safety ${ }^{(8)}$, positive parenting based on the parents' needs, improved clinical practice ${ }^{(9)}$, and valuing the testimonies of children concerning their interactions with professionals in order to understand their experience in hospitals(10).

Knowledge concerning the needs of parents, of the meaning of being involved in the care provided to hospitalized children, as well as of the perspectives of health care professionals regarding these topics, is not well disseminated in Portugal. Therefore, this study's objective was to analyze the opinions of parents or caregivers and health care professionals (nurses and doctors) concerning the involvement of parents in the care provided to hospitalized children in Portuguese hospitals.

\section{Method}

This is an exploratory study based on the conceptual framework of pediatric healthcare with qualitative analysis of data(11). It focused on the recognition of the needs of parents during the hospitalization of their children from the perspective of rights and responsibilities, to analyze the meaning of the involvement of parents in the care provided to hospitalized children.

Pediatric healthcare provided during hospitalization is not restricted to an individual perspective; rather it comprises the sick child, the parents and significant others, along with the social-cultural context of the care $^{(11)}$. In this approach, the parents and family are seen as citizens in their own right and as the primary caregivers of children. In the case of an illness, this bilateral relationship acquires a new actor, the health worker, with whom both parents and child need to interact.

The study was conducted in the pediatric services of three hospitals in Portugal: one children's hospital and another two hospitals with pediatric services. A questionnaire with open questions was applied by one of the researchers to collect data from parents and caregivers during the hospitalization of their children. Those individuals able to read and write in Portuguese and accompanying hospitalized children who were admitted for more than 48 hours were included in the study. Parents or caregivers of terminal children or parents or caregivers who, according to the nurses assessment, lacked the emotional conditions to answer the instrument, or immigrants who did not master spoken and written Portuguese, were excluded from the study. Inclusion criteria for nurses and doctors were: nurses who worked for more than 6 months in pediatric units, pediatric doctors and doctors whose specialty was pediatrics, with more than 2 years in the profession.

The questionnaire was delivered in a sealed envelop to all those who met the inclusion criteria. The following questions were asked to the parents or caregivers: What do you understand involvement of parents in the care delivered to your hospitalized child to be? (Q1); In what care activities delivered to your child would you like to take part? (Q2); What do you think could be done to improve care provided to your child during and after hospitalization? (Q3). The health care professionals answered the following questions: What do you understand involvement of parents in the care provided to hospitalized children to be? (Q4); What strategies do you use to involve the parents in the care provided to children during hospitalization? (Q5); In regard to your hospital, what do you think could be done to improve the care provided to children during hospitalization? (Q6)

A convenience sample was used. It was composed of 660 parents/caregivers and 95 health care professionals. Response rates for the answers to the questionnaire's open questions were between $7 \%$ and $81 \%$ (Table 1 ). This study is part of an investigation designed to validate an instrument with this sample size to assess the needs of parents ${ }^{(7)}$. 
Table 1 - Rate of answers to the questionnaire open questions, Portugal, 2011

\begin{tabular}{cccc}
\hline Questions & Returned & Answered & $\begin{array}{c}\text { Response } \\
\text { rate (\%) }\end{array}$ \\
\hline $\begin{array}{cccc}\text { Parents/Caregivers } \\
\text { Q1 }\end{array}$ & 660 & 392 & 59.4 \\
Q2 & 660 & 81 & 12.3 \\
Q3 & 660 & 44 & 6.6 \\
Health care professionals & & & \\
Q4 & 95 & 77 & 81.1 \\
Q5 & 95 & 74 & 77.9 \\
Q6 & 95 & 64 & 67.4 \\
Q7 & 95 & 66 & 69.5 \\
\hline
\end{tabular}

Data analysis was based on content analysis and the QSR N8NUD*IST program (Qualitative Research Software Non-Numerical Unstructured Data Indexing Search Theorizing)(12) was used. The procedures consisted of indexing information concerning the answers to the open questions, the code of which followed a logic tree structure in which the nodes are considered dimensions and are subdivided into domains, categories and subcategories. This process enabled highlighting themes and units, which in turn enabled the analysis of opinions, attitudes, values and beliefs ${ }^{(13)}$.

Ethical guidelines were complied with in this study, including seeking permission from the hospitals' Board of Directors and Institutional Review Boards. All the participants signed free and informed consent forms.

\section{Results}

\section{Sample characterization}

The caregiver sample was composed of mothers $(82 \%)$, fathers $(17 \%)$ with only $1 \%$ consisting of other persons. The average age was 33 years old, $86 \%$ were married or cohabited, the average household was composed of 3 or 4 people (78\%), with complete primary school or incomplete middle school (63\%), most had a family income <1000€ $(68 \%)$, with good socioeconomic status ( $82 \%)$, according to Graffar's classification, and lived less than $50 \mathrm{~km}$ from the hospital (88\%).

In regard to the health care professionals, $86 \%$ were nurses, $14 \%$ were doctors, $93 \%$ were women aged between 24 and 56 years old, 35\% were qualified in pediatrics, and $76 \%$ had worked in the profession for more than 6 years.

\section{Taxonomy of results}

The results emerged from the systematization of data in a process in which the meanings concerning the involvement of parents in the care provided to hospitalized children derived from dimensions, domains and categories (Figure 1).

The relative frequency of each dimension is presented in Figure 2 for each of the samples (parents/ caregivers and health care professionals).

\begin{tabular}{|l|l|l|}
\hline \multicolumn{1}{|c|}{ Dimension } & \multicolumn{1}{c|}{ Domain } & \multicolumn{1}{c|}{ Category } \\
\hline Hospital daily life & Strategies and approaches & $\begin{array}{l}\text { - Communication between parents and health care professionals } \\
\text { - Guidance and teaching } \\
\text { - Primary nurse }\end{array}$ \\
\cline { 2 - 3 } & Hospital infrastructure & $\begin{array}{l}\text { - Environment } \\
\text { - Human resources }\end{array}$ \\
\hline Involvement of parents & Presence and participation & $\begin{array}{l}\text { - Needs of and benefits for the child and family } \\
\text { - Information needs } \\
\text { - Responsibility and right to health }\end{array}$ \\
\cline { 2 - 3 } & & - Family and nursing care \\
\cline { 2 - 3 } & Performance of care activities & - Cooperation and relief of workload \\
\cline { 2 - 3 } $\begin{array}{l}\text { Continuity of care after } \\
\text { discharge }\end{array}$ & Communication between parents and health services & $\begin{array}{l}\text { - Shared learning } \\
\text { - Support provided by health services }\end{array}$ \\
\cline { 2 - 3 } & Follow-up after discharge & - Homecare and home visits \\
\hline
\end{tabular}

Figure 1 - Presentation of dimensions, domains and categories concerning the involvement of parents in the care delivery

\begin{tabular}{|l|c|c|}
\hline \multicolumn{1}{|c|}{ Dimension } & Parents/Companions & Professionals \\
\hline Hospital daily life & 42 & 240 \\
\hline Involvement of parents & 574 & 252 \\
\hline Continuity of care after discharge & 16 & 74 \\
\hline
\end{tabular}

Figure 2 - Distribution of units of each dimension according to parents/companions and health care professionals 
Three important dimensions emerged from the analysis of the qualitative data: (i) daily care provided to hospitalized children; (ii) opinions concerning the involvement of parents in the care provided to hospitalized children; and (iii) continuity of healthcare provided to children after discharge, which are presented separately for the units that concern the answers of parents $(P)$ and health care professionals (HCP).

\section{Daily care provided to hospitalized children}

Daily care provided to hospitalized children refers to aspects such as the strategies and approaches developed in the interaction between parents and health care professionals and also refers to the environment and human resources available in the hospital unit, demonstrated by the following:

Communication among the physician, nurse and parents is very important. (P 88)

An open dialogue during the visits with the physician, the nurses responsible for the treatment and follow-up. (P 204)

Aside from communication, teaching, and orientation, the professionals also mention strategies focused on health education and training parents to provide care to children.

It is important to share knowledge and information with them, leading them to participate in care through health education, supporting them, and always advising. (HCP 34)

The primary $\mathrm{RN}$ is mentioned as a way to organize nursing care.

There should be a primary nurse who'd always attend to the child and family so that parents would feel at ease expressing their doubts and fears, enabling them to become more involved in the care provided to the child. (HCP 12)

The accommodations, space and privacy of children within the hospital are mentioned in regard to the hospital infrastructure. The parents believe that the environment does not meet the needs of their children and their respective companions.

Better conditions: air conditioning, better bathrooms, better beds, and better eating tables. (P 305)

During hospitalization, there is no private place to report and collect data from the mother or child, or to confide anything that requires a calmer or private place. $(P 5)$

In regard to human resources, the interviewees highlight the allocation of nurses, doctors and other technicians.

It is important that the allocation of personnel is reviewed whenever there is a need of longer hours of care; that is, the number of professionals available should not be the same when there are 5 inpatients and when there are 20 children. (HCP 21)

There should be more nursing personnel and doctors so they have sufficient time to perform all the functions inherent to hospitalization (HCP 27)

The reports emphasize the need to increase the number of nurses and doctors, adjusting their allocation according to the number of hospitalized children and to the activities specific to each child.

\section{Opinions concerning the involvement of parents in the care provided to hospitalized children}

The opinions concerning parental involvement comprise aspects related to the presence, participation, needs and benefits for the child and parents, their information needs, responsibility and right to health, performance of care activities, and help provided to health care professionals.

Some parents consider involvement only to mean constant monitoring and companionship.

Involvement means to be a companion, to be with him 24 hours a day. (P 23)

Parents should be present because children like to be with their parents when they are hospitalized. ( $P$ 451)

Involvement linked to the idea of participation indicates an opportunity for the parents to take part in the care provided to children in an active and informed way, as a partnership.

Active participation in care delivery. An open dialogue with the health care professionals. Detailed information concerning the progress of our child's health status. (P 204)

Partnership in child-centered care is indeed added value to the child's wellness. (HCP 64)

The parents express some specifics concerning effective participation in pediatric units, such as teaching and supervision provided by professionals in a personalized way, adjusted to the child's context, centered on the family, inducing decision-making.

I understand that parents should participate in care delivery as long as they feel prepared to do it and always with the supervision of doctors and nurses. (P 254)

I understand that this involvement should not be universal since not all parents respond the same way. ( $\mathrm{P}$ 316)

The presence and participation of parents during hospitalization also seek to attend the child's needs and benefit the child by ensuring her/his safety.

I understand by involvement of parents in the care provided to hospitalized children the participation of parents in all the tasks and the supply of information concerning the child, namely the child's favorite games, sleep and feeding 
rituals. The involvement of parents enables preserving the child's emotional sphere and affective exchanges in order to encourage the relationships among the child, the parents and the nurse. (HCP 53)

There are situations in which the parents exhaust their energies while being here. There should be understanding in these cases because parents need a lot of support. (HCP 56)

Presence and participation presuppose information, which refers to the need for parents to have clinical knowledge concerning the child's health.

I understand that parents should have full knowledge, be fully informed and clear about the disease, the cause of the disease, and potential consequences so as to contribute and also make decisions on how to fight the disease and be prepared for future situations. (P 603)

The involvement of parents is also related to the responsibility assigned to them and to their right to take part in decision-making.

I understand that the parents have the duty and the right to constantly accompany their child as a way to ensure they have the emotional support they are used to, helping them to understand new physical sensations they will experience. ( $\mathrm{P}$ 658)

After being properly informed, give their opinion on the treatment, pros and cons and not be passive elements who just accept orders. (HCP 8)

The involvement of the parents in the child's hospitalization was also discussed in terms of performing some procedures.

The involvement of the parents in care delivery means they are actively promoting the child's hygiene and comfort, being attentive to the medication schedule, and positioning the child in bed. (HCP 66)

The help parents provide to health care professionals through cooperating with procedures and constantly monitoring the child also appears as involvement, which helps to alleviate the workload of the professionals and is subject to a process of negotiation.

Helping the nurses control antibiotics, taking temperature, etc., and helping with care procedures that are nothing for us but that help them. (P 106)

It means to allow the parents to take part in the care provided to their children after the nurse has shown examples and under the nurse's monitoring. For that, there has to be negotiation. (HCP 12)

The reports show that the involvement of parents takes place after the health care professionals authorize them to do so, suggesting that the purpose of sharing care delivery with the parents is centered on the professionals and not on the parents.

\section{Continuity of healthcare provided to the child after discharge}

In regard to the continuity of care provided to the child after discharge, the following aspects were highlighted in relation to the inter-relationship between parents and health services, namely: shared learning; support for parents to care for the child at home; and home visits. The process of learning how to provide care during hospitalization is valued by the parents so that they can continue to care for their child at home, emphasizing that communication is important for problem-solving.

Learning some things that are important and that we can even do at home. (P 463)

After discharge, the child should have support from the staff that provided care in case there is some doubt or complication at home. (P 140)

Learning to do things, I think about it when we'll have to do it at home. (P 54)

[...] it's important to learn and participate in all the care activities, with the exception of nursing procedures, because these are responsibility of technicians. I help with the shower and medication because I'll have to do these when I'll go back home. (P 278)

The continuity of care provided to the child is also linked to the parents' preparation for discharge, to improve care provided at home and dealing with the disease.

It's during the hospitalization that we start preparing for discharge, the parents should be oriented and taught to deal with the child's disease. Seek to know whether there are doubts, reinforce the importance of ongoing care, of going back to the health unit, attending consultations, and if necessary, seeking hospitalization service. (HCP 6)

[...] we should participate in all care activities - shower and hygiene, food, checking temperature - that we're going to perform after discharge. (P311)

[...] basic healthcare, which we'll have to perform at home after discharge. It'll be a learning experience. (P593)

Involvement linked to the responsibility of parents is particularly important to ensuring the continuity of care.

We make sure that parents will be self-assured and have the autonomy and responsibility to continue the care provided to their children. (HCP 34)

The parents should became completely involved in the care provided to their children so that when they go back home they are able to provide all the assistance the child needs. (P 242) 
Home visits are considered to be a relevant practice because they connect the family to the hospital and healthcare units.

After the child's discharge, the family nurse from the healthcare unit covering the child's area of residence is called and receives a report concerning the child's hospitalization and the type of relationship between mother and child. Children at risk are now receiving home visits by the hospital nurse together with the nurse from the healthcare unit. (HCP 11)

A home visit and contact should be established with technicians after discharge. (P 725)

\section{Discussion}

The presence and participation of parents in the care provided to hospitalized children enable them to draw closer to health care professionals, a situation in which communication and mutual understanding is key. Such aspects are emphasized in this study and are in consonance with other studies ${ }^{(4-5,14)}$

The involvement of parents in the care provided to hospitalized children has many forms of expression. When communication between health care professionals and the family is efficient, parents experience less anxiety and become more inclined to get involved, which in turn encourages their autonomy, treatment adherence, and the coping process ${ }^{(5)}$.

Orientation and qualification provided by nurses to the parents of hospitalized children tend to reassure parents that they are capable of providing care to their child, who becomes more participative and responsible $e^{(9,15)}$. The presence of parents or companions is a source of protection and security for the child(10,16).

There is, in the hospital context, a concern over the management of human resources, leading hospital facilities to establish strategies in order to reconcile efficiency in care delivery, cost reduction, quality of healthcare, and patient satisfaction(15). Even though child- and family-centered care is the paradigm in current pediatric nursing care ${ }^{(17)}$, one study shows that nurses require organizational support and specific guidance to apply these principles in clinical practice, which can be an obstacle to the involvement of parents. Other studies show that, on one hand there is a lack of privacy and family isolation but, on the other hand, there is satisfaction from parents and their gratitude for the opportunity to remain with the hospitalized child and to take part in the care provided to her/him(6,15).
The primary nurse should be focused on the nurse's autonomy and responsibility to lead the care process together with other nurses, collaborating with a broadened view with the expectation of continuity of care during hospitalization, with assessment, planning, execution, progress and supervision ${ }^{(18)}$.

Families increasingly show interest in being included in care delivery, which implies the establishment of bonds and partnerships, and the valorization of health care professionals' listening abilities, which contributes to the humanization of healthcare provided to hospitalized children $^{(1-2,19)}$.

Even though the presence of parents is encouraged in health facilities, it may be hindered by fear health care professionals feel regarding the participation of parents in care delivery, which is related to the "transference" of competencies from professionals to the parents. One study(20) shows that humanized care during hospitalization is related to the ability to approach individuals holistically and equally, while non-humanized care is permeated by attitudes that value hospital rules, lack of attention, and lack of empathy on the part of professionals.

From the perspective of health care professionals, parents can take part in care delivery given some assumptions, that is, after the procedure is explained, and following an example provided by nurses, parents may participate when nurses have the opportunity to supervise the parents' performance. The performance of technical procedures requires more complex learning processes $^{(18)}$ to enable parents to deal with new contexts and requirements ${ }^{(15)}$, considering them partners in the care provided to the child.

The understanding achieved in this study is that assigning care activities to parents does not amount to lack of professional responsibility because it implies supervision and a division of activities, with an opportunity to identify difficulties and promote health.

The delivery of care to hospitalized children requires partnership and the consideration of other kinds of knowledge (that of the family and the child) based on the action of those involved in the process and to strengthen the competencies of the family ${ }^{(21)}$.

\section{Final considerations}

Current paradigms concerning child healthcare recommend the presence of parents in hospital units, their participation in care and involvement in the entire 
process of the child's life, reinforcing parenting and strengthening the inclusion of subjects in care and human rights.

Parents are eager for information, valuing all aspects related to the child's health condition and knowledge concerning the implications that diseases may have in the future. When health care professionals do not have a clear understanding of what parents value, they hinder the possibility of effective response to their needs, possibly contributing to the parents' distress and insecurity.

It is essential that health care professionals appropriate these changes and new knowledge and incorporate them into their strategic practices in order to encourage the involvement and participation of parents in care delivery, according to the needs of each child and family, sharing knowledge, promoting health, and contributing to humanized and quality healthcare.

This study contributes to knowledge concerning the involvement of parents in the care provided to hospitalized children. Further studies are required to continue investigating strategies that promote the involvement of parents and also consider the involvement of children in self-care.

\section{References}

1. Aein F, Alhani F, Kazemnejad A. Parental participation and mismanagement: a qualitative study of child care in Iran. Nurs Health Sci. 2009;11(3):221-7.

2. Sikorova L, Kucova J. The needs of mothers to newborns hospitalized in intensive care units. Biomed Pap Med Fac Univ Palacky Olomouc Czech Repub. 2012;156(4):330-6.

3. Huhtala M, Korja R, Lehtonen L, Haataja L, Lapinleimu $\mathrm{H}$, Munck $\mathrm{P}$, et al. Parental psychological wellbeing and cognitive development of very low birth weight infants at 2 years. Acta Paediatric. 2011;100:1555-60.

4.Torquato IMB, Jonas MF, Collet N, Pinto MB, Santos NCCB, Morais GSN. A doença e a hospitalização infantil: compreendendo o impacto na dinâmica familiar. Rev Enferm UFPE On Line. [Internet]. 2012 [acesso 17 fev 2013]; 6(11):2641-8. Disponível em: http://www. revista.ufpe.br/revistaenfermagem/index.php/revista/ search/results

5. Araújo YB, Collet N, Moura FM, Nobrega RD. Conhecimento da família acerca da condição crônica na infância. Texto e Contexto Enfermagem. 2009; 18(3):498-505.
6. Power N, Franck L. Parent participation in the care of hospitalized children: a systematic review. J Adv Nurs. 2008;62(6):622-41.

7. Ferreira PL, Melo EMOP, Reis G, Mello DF. Validação e análise da precisão da versão em português do Needs of Parents Questionnaire. J Pediatria. 2010;86(3):221-7.

8. Wegner W, Pedro ENR. Patient safety in care circumstances: prevention of adverse events in the hospitalization of children. Rev. Latino-Am. Enferm. 2012;20:427-34.

9. Lopes MSOC, Dixe MACR. Positive parenting by parents of children up to three years of age: development and validation of measurement scales. Rev. Latino-Am. Enferm. 2012;20(4):787-95.

10. Norena Peña AL, Cibanal JL. The experience of hospitalized children regarding their interactions with nursing professionals. Rev. Latino-Am. Enferm. 2011;19(6):1429-36.

11. Kristjánsdóttir G. Perceived importance of needs expressed by parents of hospitalized two- to six- yearolds. Scand J Caring Sci. 1995;9(2):95-103.

12. Bazeley P. Qualitative data analysis with NVivo. London: Sage Publications; 2007.

13. Turato ER. Métodos qualitativos e quantitativos na área da saúde: definições, diferenças e seus objetos de pesquisa. Rev Saúde Pública. 2005;39(3):507-14.

14. Fegran L, Helseth S. The parent-nurse relationship in neonatal intensive care unit context: closeness and emotional involvement. Scand J Caring Sci. 2009;23(4):667-73.

15. Molina RC, Marcon SS. Benefícios da permanência de participação da mãe no cuidado ao filho hospitalizado. Rev Esc Enferm USP. 2009;43(4):856-64.

16. Murakami R, Campos CJG. Importância da relação interpessoal do enfermeiro com a família de crianças hospitalizadas. Rev Bras Enferm. 2011;64(2):254-60.

17. Trajkovski S, Schmied V, Margaret V, Jackson D. Neonatal nurses' perspectives of family-centered care: a qualitative study. J Clin Nurs. 2012;21:2477-87.

18. Assis M, Collet N, Sila K, Moura F. Cotidiano da família no enfrentamento da condição crônica na infância. Acta Paul Enferm. 2010;23(3):359-65.

19. Faquinello $\mathrm{P}$, Higarashi IH, Marcon SS. O atendimento humanizado em unidade pediátrica: percepção do acompanhante da criança hospitalizada. Texto Contexto - Enferm. 2007;16(4):609-16.

20. Melo E, Martins F, Pleno A, Fontoura C, Seabra F. Cuidados centrados na criança e família: o papel do enfermeiro de referência. Linhas de Saúde. 2009;1:24-6. 
21. Collet N. Sujeitos em interação no cuidado à criança hospitalizada: desafios para a Enfermagem Pediátrica.

Rev Bras Enferm. 2012;65:7-8. 